\title{
Un rapport difficile à la diversité dans l'école de la République
}

Approche sociohistorique du modèle français

The difficult issue of diversity in school. A socio-historic approach of the French republican model

Una difícil relación con la diversidad en la Escuela de la República.

Aproximación sociohistórica al modelo francés

\section{Olivier Meunier}

\section{OpenEdition Journals}

Édition électronique

URL : http://journals.openedition.org/ries/3486

DOI : $10.4000 /$ ries.3486

ISSN : 2261-4265

\section{Éditeur}

Centre international d'études pédagogiques

\section{Édition imprimée}

Date de publication : 1 septembre 2013

Pagination : 89-98

ISBN : 978-2-85420-600-5

ISSN : $1254-4590$

Référence électronique

Olivier Meunier, « Un rapport difficile à la diversité dans l'école de la République », Revue internationale d'éducation de Sèvres [En ligne], 63 | septembre 2013, mis en ligne le 01 septembre 2015, consulté le 01 mai 2019. URL : http://journals.openedition.org/ries/3486 ; DOI : 10.4000/ries.3486 


\section{Un rapport difficile à la diversité dans l'école de la République}

\section{Approche sociohistorique du modèle français}

\section{Olivier Meunier}

Le modèle de la forme scolaire en France, hérité de la Troisième République, présente une tendance récurrente de résistance à la reconnaissance de la diversité culturelle par crainte d'une remise en cause de la cohésion nationale, sa mission étant de transmettre les valeurs républicaines aux futures générations, afin d'en faire des citoyens d'une nation porteuse d'une culture commune. L'instruction se veut nationale et laïque et s'adresse à des individus, le droit français ne reconnaissant ni groupe, ni minorité, ni communauté, à l'exception des associations (Loi de 1901). Cela implique que chaque enfant laisse à la porte de l'école ses caractéristiques socioculturelles singulières, afin d'accéder à la citoyenneté et aux connaissances rationnelles présentées comme universelles, l'uniformisation dans le creuset républicain étant le but recherché. Il s'agit avant tout de sauvegarder un consensus social, justifié par la mise en avant des notions de justice et d'égalité, en permettant aux élèves de disposer d'une instruction commune de base préparant leur vie dans la société.

Nous allons présenter, commenter et analyser, dans une perspective historique (de 1970 à 2013) et sociopolitique, la capacité de l'école républicaine à reconnaître, à prendre en considération et à accueillir la diversité des cultures et des identités qui façonnent la société française en dehors de ses murs.

Les années 1970 représentent une période où il s'agit soit d'assimiler les élèves de parents étrangers au creuset républicain, soit de les marginaliser en pensant qu'ils retourneront dans leur pays d'origine. Dans les années 1980, l'école française reconnaît la diversité culturelle et s'ouvre à différents partenaires extérieurs, comme les parents, les associations et les communautés urbaines, tandis que des zones d'éducation prioritaires (ZEP) sont créées, afin de donner plus de moyens à la scolarisation de ceux qui sont culturellement et socialement éloignés de la forme scolaire. Après la multiplication du phénomène du port du foulard islamique en 1989, les années 1990 représentent un retour à la rhétorique républicaine visant à l'intégration des élèves avec une posture d'indifférence aux différences, si ce n'est sociales, avec la poursuite de la discrimination positive de l'éducation prioritaire. À partir des années 2000, la diversité culturelle est prise en considération dans la formation des enseignants, dans le socle commun de compétences et les curricula de l'école maternelle au lycée, 
mais les pratiques pédagogiques interculturelles demeurent limitées et hétérogènes selon les écoles et les classes, dépendant de la bonne volonté, de la motivation et de l'intérêt des acteurs du système éducatif. En 2013, la loi Peillon sur l'orientation de l'éducation, intègre finalement, sous la pression de la société civile, l'enseignement des langues et des cultures régionales dans l'enseignement, conformément à la Charte des langues régionales ou minoritaires du Conseil de l'Europe ratifiée par la France. Il est intéressant de noter que les langues de la migration ne sont pas intégrées dans la loi.

\section{ASSIMILATION OU MARGINALISATION DANS LES ANNÉES 1970}

Après la Seconde Guerre mondiale, durant la période des «trente glorieuses », les besoins de main-d'œuvre entraînent une politique favorisant l'immigration de travailleurs (ordonnance du 2 novembre 1945), principalement issus des anciennes colonies, tout en leur accordant la naturalisation, conformément au droit du sol.

Dans les années 1970, la crise économique entraîne la progression d'un chômage jusqu'à lors quasi inexistant, ce qui amène les autorités à suspendre en 1974 la politique d'immigration et à stabiliser la population étrangère. Dans ce contexte, des dispositifs visant à favoriser l'accueil des enfants de l'immigration dans les écoles et à reconnaître les cultures dites d'origines sont mis en place : la diversité culturelle est prise en considération... mais d'une manière singulière.

Ainsi, en 1975, sont instaurés les enseignements de langue et de culture d'origine (ELCO) dans le cadre d'une politique de regroupement familial des immigrés visant à faciliter la réinsertion des enfants de l'immigration dans leurs pays d'origine et dans leur appartenance nationale. Ces enseignements sont organisés par les ministères de l'Éducation des pays d'origine soucieux de conserver un contrôle sur leur population émigrée dans le cadre de leur politique de construction nationale et d'émancipation à l'égard de la France. Ils sont assurés trois heures par semaine dans les établissements scolaires français, à la place d'activités d'éveil (circulaire du 2 février 1973). Les ELCO ne cherchent pas à travailler la reconnaissance de la diversité culturelle comme facteur d'enrichissement interculturel et relèvent de ce fait d'une approche différentialiste et parfois même essentialiste : les cultures d'origine sont considérées comme des ensembles symboliques clos censés correspondre à ceux des élèves migrants et de leur famille. Cependant, la langue et la culture de référence des élèves migrants ne correspondent pas toujours à celles de leur milieu familial, comme cela a pu être le cas d'enfants berbères recevant un enseignement d'enseignants arabes. En continuant à être traités officiellement comme des ressortissants de pays étrangers, ces élèves et leurs familles se voient constamment imputer une différence et renvoyés de ce fait à leurs origines. 
Entre 1975 et 1984, vingt centres de formation et d'information pour la scolarisation des enfants migrants (CEFISEM) sont créés comme sections pédagogiques des écoles normales : ils ont pour vocation d'accueillir les maîtres étrangers enseignant les langues nationales, mais aussi les maîtres français des classes d'initiation et de cours de rattrapage.

Concernant les familles immigrées qui choisissent de rester sur le territoire français, le ministère de l'Éducation va mettre en place des dispositifs favorisant l'assimilation des élèves migrants dans la société française avec la création de classes d'initiation (CLIN) - permettant l'alphabétisation et l'apprentissage des bases du français - et de cours de rattrapage intégré (CRI) - donnant lieu à quelques heures de français en plus de l'enseignement ordinaire dans les écoles élémentaires -, et d'enseignement de soutien et de classe d'adaptation (CLA) dans les collèges (circulaire du 13 janvier 1970).

L'idée sous-jacente est d'assimiler ces élèves à la nation française dans le cadre de l'unité linguistique nationale, et donc les insérer le plus rapidement possible dans les classes ordinaires. La diversité culturelle n'est néanmoins pas valorisée puisqu'il s'agit avant tout d'intégrer des élèves porteurs de cultures différentes.

\section{UNE APPROCHE INTERCULTURELLE AVORTÉE}

Ce n'est qu'avec l'avènement de la circulaire du 25 juillet 1978 que le terme interculturel est utilisé dans un texte officiel. Elle élargit les activités des ELCO dans une perspective interculturelle en s'adressant à l'ensemble des élèves. Cet élargissement découle, d'une part, de l'influence des travaux du Conseil de l'Europe qui incite les États à développer une orientation interculturelle en milieu scolaire et à favoriser une prise de conscience de l'intérêt d'une ouverture réciproque sur les identités culturelles; d'autre part, du constat d'échec de la politique d'incitation au retour des immigrés dans leurs pays d'origine. Par ailleurs, les acteurs du système éducatif estiment que les ELCO ont plutôt renforcé le sentiment de mise à l'écart et de non intégration des enfants de parents immigrés. Ils vont donc proposer d'élargir les pratiques interculturelles et l'instauration de cours de langue et de culture d'origine ou étrangère à l'ensemble des élèves afin de valoriser les cultures des élèves migrants, renforcer leur intégration et lutter contre l'échec scolaire les concernant.

Cette circulaire favorise la promotion d'une pédagogie interculturelle dans tous les degrés de l'enseignement et autorise l'organisation d'activités interculturelles destinées à l'ensemble des élèves avec le concours des ELCO. Elle précise que les langues et les cultures étrangères peuvent être considérées comme des facteurs d'enrichissement pour les élèves français afin qu'ils puissent s'ouvrir à d'autres cultures et à la contribution de celles-ci au savoir universel. Concernant les enfants de parents de l'immigration, elle indique que la reconnaissance 
de leur culture ne risque pas de les éloigner de la culture française, que la pratique de deux langues et le contact avec les deux cultures peuvent donner lieu à une scolarité enrichissante. L'interculturalité est présentée comme une ouverture d'esprit dont la finalité serait de favoriser la compréhension réciproque des nationalités présentes à l'école, mais aussi dans la société.

Cependant, cette orientation n'est pas suivie dans les faits parce que les ELCO ont continué à s'adresser uniquement aux enfants de migrants du fait des accords diplomatiques existants avec les pays d'origine (Kerzil \& Vinsonneau, 2004 : 71). La dimension interculturelle est ainsi réduite à un travail pédagogique ciblé sur des cultures exogènes dont certains élèves sont porteurs, avec souvent un folklorisme qui permet rarement de développer une reconnaissance de la diversité, un travail sur l'altérité, une approche dynamique des cultures (Abdallah-Pretceille, 1999: 82).

Si la notion d'éducation interculturelle est officiellement écartée en 1984 par le Ministère de l'Éducation, elle demeure présente dans les textes du Conseil de l'Europe et de la Commission européenne ainsi que dans les milieux associatifs en France. Sur le terrain, elle est souvent circonscrite aux actions développées par un enseignant ou une école, avec l'objectif de favoriser des relations positives d'interaction, de coopération et de compréhension entre des élèves provenant de différentes cultures.

Les classes d'initiation et d'adaptation demeurent peu efficaces en raison de l'absence de pertinence des méthodes pédagogiques et des contenus curriculaires, du manque de formation des enseignants et de leur faible nombre. De plus, la manière de sélectionner leurs élèves et l'absence d'articulation avec les curricula des classes ordinaires favorisent le retard scolaire de nombreux élèves issus de l'immigration (Boulot \& Bozon-Fradet, 1988), et par voie de conséquence, leur relégation dans des classes de perfectionnement au primaire ou dans les sections de l'enseignement spécialisé au secondaire (Vallet \& Caille, 1996).

\section{RECONNAISSANCE DE LA DIVERSITÉ CULTURELLE DANS LES ANNÉES 1980}

Dans les années 1980, la notion de diversité devient récurrente dans les textes officiels, tandis que l'école s'ouvre à des partenaires extérieurs (associations, parents d'élève, villes). La prise de conscience que les sociétés sont de plus en plus multiculturelles amène un regard nouveau sur l'éducation : il s'agit alors de préparer chaque élève à la diversité, à l'altérité et à la reconnaissance de l'autre en tant que sujet singulier et universel. Comme l'éducation interculturelle a tout d'abord concerné les enfants de migrants dans les années 1970, cette orientation a contribué à occulter d'autres formes de diversité culturelle, comme la construction européenne, l'accroissement des échanges internationaux, les 
cultures régionales, générationnelles, professionnelles... Au niveau pédagogique, la reconnaissance des caractéristiques individuelles de chaque élève est considérée comme essentielle à l'appropriation des savoirs, ce qui implique que l'enseignant puisse se centrer sur l'apprenant et donc sur ce qu'il vit dans son environnement socioculturel.

Les ZEP sont créées en 1981 dans un contexte où la société française reconnaît sa composition multiculturelle et le droit d'expression des minorités. Sur le plan éducatif, il s'agit de prendre en compte la diversité culturelle des élèves, afin d'enrichir la culture nationale (Berque, 1985:44). On passe alors d'une logique de juxtaposition des identités culturelles (ELCO) ou d'assimilation (CLIN) dans les années 1970 à une prise en considération de la diversité culturelle des élèves dans les années 1980.

Les recommandations du comité des ministres du Conseil de l'Europe, comme celle du 25 septembre 1984 sur la «formation des enseignants à une éducation pour la compréhension interculturelle, notamment dans un contexte de migration ", vont être reprises par le ministère de l'Éducation dans le cadre de l'intégration des enfants d'immigrés à l'école. Cependant, les différents principes mis en avant (dialogue et compréhension interculturelle, reconnaissance de la diversité et du relativisme culturel, refus de l'ethnocentrisme, respect de la valeur et de l'originalité de chaque culture) n'étant pas travaillés sociologiquement et demeurant peu instrumentés pédagogiquement, donnent lieu à une lecture stéréotypée des différences en les durcissant au lieu de prendre en compte leur fluidité (Lorcerie, 2003 : 261-262).

Cependant, durant les années 1980, différentes notes ministérielles visent à amener les élèves à être sensibilisés aux problèmes du tiers-monde, aux relations interculturelles basées sur la solidarité, mais aussi à mieux comprendre l'évolution des sociétés. Des échanges de classes sont organisés, principalement avec des pays européens avec l'objectif d'un enrichissement linguistique et culturel. Les directives du ministère de l'Éducation nationale vont recommander la prise en compte des cultures locales dans les dispositifs de l'éducation prioritaire, les établissements sensibles et les quartiers défavorisés.

Ces mesures vont provoquer quelques changements dans la formation initiale et continue des enseignants. Des missions académiques à la formation des personnels de l'Éducation nationale (MAFPEN) et des instituts universitaires de formation des maîtres (IUFM) vont organiser des formations, des groupes de travail et des stages sur les cultures des immigrés ou sur les relations entre enseignants et parents immigrés. L'objectif est de mieux connaître les cultures des élèves migrants pour un meilleur fonctionnement du système éducatif. Ces formations vont donner lieu, dans certains établissements, à un traitement différent des élèves migrants et à de nouvelles formes d'accueil des parents immigrés : modification des contenus et de la forme des réunions et des entretiens avec les parents, utilisation de traducteurs et de médiateurs (Auduc, 1996). 
Le rapprochement entre l'école, les familles et les collectivités locales, dans le contexte du contrat éducatif local, va également favoriser une ouverture des enseignants et des écoles aux spécificités et aux besoins des familles et des élèves immigrés issus notamment des classes populaires (Van Zanten, 1997 : 156).

\section{LE RETOUR À LA RHÉTORIQUE DE L'INTÉGRATION DANS LES ANNÉES 1990}

La question du port du foulard islamique en 1989 (plusieurs collégiennes de confession musulmane refusent d'enlever leur voile en classe) a pour effet un renforcement de la politique d'intégration en s'appuyant sur le principe de laïcité. Le rapport Hussenet (1990) recommande de mettre en place dans les curricula l'étude des rites et des croyances des grandes religions avec une approche objective, rationnelle et pluraliste. Le premier rapport du Haut Conseil à l'intégration (HCI) de 1991 considère l'intégration comme un processus spécifique visant à "susciter la participation active à la société nationale d'éléments variés et différents, tout en acceptant la subsistance des spécificités culturelles, sociales et morales, et en tenant pour vrai que l'ensemble s'enrichit de cette variété et de cette complexité ».

En 1993, le retour de la droite au gouvernement entraîne une nouvelle définition de l'intégration par le HCI :

« ce modèle français d'intégration procède d'un retour aux sources d'une pensée qui a refusé le déterminisme d'ethnie, de classe, de religion... il s'oppose ainsi à la logique des minorités qui confère un statut spécifique aux minorités nationales ou ethniques ».

En 1995, le HCI recommande que les ELCO soient mieux intégrés dans le service public avec un passage de l'enseignement des langues et culture d'origine à un enseignement de langues et cultures étrangères. En 2003, le rapport Stasi suggère de supprimer les ELCO.

La législation concernant les dispositifs spécifiques pour accueillir les élèves non-francophones nouvellement arrivés en France est modifiée le 20 mars 2002 : il est précisé que l'État garantit à l'enfant « le droit à l'éducation en dehors de toute distinction qui tienne à sa nationalité ou à sa situation personnelle». Cette orientation est confirmée (circulaire du 24 avril 2002) en indiquant que l'obligation d'accueil dans les établissements scolaires s'applique à tous les élèves, qu'ils soient primo-arrivants ou gens du voyage.

Les élèves non-francophones doivent être scolarisés en classe ordinaire et bénéficier d'enseignement de français en CLIN dans le primaire ou en CLA dans le secondaire pendant moins d'un an, afin de suivre ensuite l'ensemble des enseignements en classe ordinaire. L'aspect transitoire de la scolarisation des primo-arrivants dans des structures spécifiques est réaffirmé par rapport aux textes 
de 1970 (circulaire $n^{\circ} 9$ 70-37 du 13 janvier) et de 1986 (circulaire n 86-119 du 13 mars). Ces mesures visent à restreindre les phénomènes de ségrégation propres à certains établissements ou classes, tout en évitant de confondre primoarrivants et enfants ou petits-enfants d'immigrés nés sur le territoire français.

\section{VERS UNE RECONNAISSANCE DE LA DIVERSITÉ CULTURELLE À PARTIR DES ANNÉES 2000}

Dans les années 2000, le thème de l'intégration est progressivement remplacé dans les textes officiels par la lutte contre les discriminations, le racisme et l'antisémitisme, avec comme arrière-fond le danger relatif aux communautarismes.

Les centres académiques pour la scolarisation des nouveaux arrivants et des gens du voyage (CASNAV) remplacent (circulaire du 25 avril 2002) les CEFISEM créés en 1975. Leurs activités sont recentrées sur "l'accompagnement de la scolarisation des élèves nouvellement arrivés en France sans maîtrise suffisante de la langue française ou des apprentissages scolaires des enfants du voyage ». La circulaire préconise une approche didactique de type "français langue seconde » et non plus «français langue étrangère » comme cela avait été recommandé depuis 1970.

Dans le Bulletin officiel de l'Éducation nationale (BOEN) du 4 janvier 2007

relatif à la formation des enseignants, la prise en considération de la diversité des élèves et de leurs cultures est présentée comme l'une des dix compétences que les futurs enseignants doivent acquérir :

«Le professeur connaît les éléments de sociologie et de psychologie lui permettant de tenir compte, dans le cadre de son enseignement, de la diversité des élèves et de leurs cultures ».

Les enseignants sont donc formés à la prise en compte de la diversité culturelle des élèves, mais lors des stages de formation, nous avons pu constater qu'ils oubliaient souvent qu'ils étaient également porteurs d'une culture, plus proche des attentes de l'école, qui ne leur permettait pas toujours d'appréhender la diversité sans jugements de valeurs ou a priori. Le processus de décentration par rapport à sa propre culture, nécessaire à toute posture interculturelle, y compris chez les enseignants issus de la diversité culturelle, est rarement mis en place.

À partir de la deuxième moitié des années 2000, la prise en considération de la diversité culturelle dans les curricula se développe timidement. Elle est présente dans les BOEN des 8 juin 2006, 10 mai 2007 et 19 juin 2008 concernant l'éducation à la citoyenneté, au développement durable et à la solidarité internationale.

Lors de l'année européenne du dialogue interculturel en 2008, le BOEN du 13 mars précise que l'éducation artistique et culturelle a pour objectif de 
«favoriser l'appréhension par les élèves de la diversité culturelle comme facteur d'enrichissement mutuel ", tandis que la Cité nationale de l'histoire de l'immigration - récemment inaugurée - est considérée comme un carrefour des " thématiques de la diversité culturelle et du dialogue interculturel », ainsi qu'un support à l'enseignement de l'histoire de l'immigration.

Les questions relatives à la diversité culturelle sont abordées dans les programmes dès l'école maternelle, notamment en éducation civique (ouverture à l'autre et respect de la différence) et en langage (traditions orales régionales et des aires culturelles des enfants étrangers ou d'origine étrangère qui fréquentent l'école, familiarisation avec la diversité des cultures et des langues).

Le cycle 2 de l'école élémentaire questionne le vivre ensemble dans le cadre d'une éducation à l'altérité, mais aussi la diversité des milieux et des modes de vie et la familiarisation avec la diversité des cultures et des langues. Le cycle 3 en éducation civique souligne l'importance de l'écoute de l'autre comme première forme de respect et d'acceptation de la différence, tandis que l'histoire traite de la civilisation islamique, du massacre des Indiens d'Amérique, de la traite des noirs, de l'émigration et de l'expansion coloniale, en montrant les conflits mais aussi les échanges qu'ils engendrent.

Avec la mise en place du socle commun de compétences en 2006-2007, le cinquième axe relatif à la culture humaniste porte sur la compréhension de l'unité et de la complexité du monde par une approche de la diversité des civilisations, des sociétés, des religions ainsi que du fait religieux, en s'inspirant des textes fondateurs (Bible, Coran) dans un esprit de laïcité respectueux des consciences et des convictions. L'axe 6 sur les compétences sociales et civiques insiste sur le principe de laïcité et sur le respect des autres, au fondement de la vie en société.

Au collège, l'histoire, la géographie, le français s'ouvrent au monde (notamment musulman, mais pas uniquement), et l'éducation civique traite du refus des discriminations, des Droits de l'Homme et de la citoyenneté européenne. Au lycée est abordée, en histoire, la diversité des contacts et des influences culturelles dans l'aire méditerranéenne au XII ${ }^{e}$ siècle ; en géographie, les questions de mobilité des hommes dans l'Union européenne, des migrations à caractère économique ou politique, des relations Nord/Sud; en éducation civique, la citoyenneté, les formes de la mondialisation avec les notions d'acculturation et de différenciation culturelle ; en philosophie, les notions de l'universel et du singulier, de l'identité, de l'égalité et de la différence ; en sciences économiques et sociales, la culture en tant que transmission et construction collective, ainsi que les notions d'acculturation et de différenciation culturelle.

Cette reconnaissance partielle de la diversité culturelle semble plus présente dans le primaire que dans le secondaire, où le découpage disciplinaire tend à limiter les approches transversales.

Les valeurs républicaines de l'intégration et les dangers du communautarisme, notamment de l'islam radical, ont par ailleurs été renforcés dans les 
curricula, et si les principales religions monothéistes sont étudiées, ce n’est pas le cas des autres religions.

Le principe de laïcité est cependant affirmé comme creuset égalitaire de la liberté de culte ou d'absence de culte, où toute forme de prosélytisme ou d'obscurantisme doit être écartée par une approche scientifique et sociohistorique des religions.

Les approches interculturelles perdurent principalement dans les "éducations à ... ", comme l'éducation au développement durable, l'éducation à la citoyenneté, mais aussi en langage, au primaire, où la diversité linguistique et culturelle est valorisée (depuis 2013).

Depuis la masteurisation de la formation des enseignants (nécessité de disposer d'un master 2 pour passer le concours de professeur des écoles) en 2010, des séminaires de recherche ont été mis en place dans les IUFM, certains portant sur les questions d'identité et de diversité culturelle à l'école, tout en demeurant optionnels. Avec la nouvelle réforme de 2013 transformant les IUFM en ESPE (écoles supérieures du professorat et de l'éducation), les contenus théoriques diminuant pour faire place à des stages pratiques à la demande des étudiants et de certains enseignants, ces séminaires de recherche ont disparu et les questions relatives à la diversité culturelle tendent à être dissoutes dans des unités d'enseignement significativement réduites (de 24 heures à 18 heures semestrielles) et déjà très chargées en contenu.

À partir des années 1970, différentes modalités prenant en compte la diversité ont été mises en œuvre, visant soit à assimiler (CLIN), soit à différencier (ELCO) les élèves de parents immigrés. Ce n'est qu'à partir de 1978 que des activités interculturelles sont proposées à l'ensemble des élèves. Alors que la société française commence à intégrer des éléments favorisant l'ouverture à la diversité culturelle (sensibilisation des élèves aux problèmes des pays en développement en 1985), certains évènements ( foulard islamique » en 1989) vont favoriser la décision du ministère de l'Éducation nationale de retirer le terme « interculturel », jugé politiquement inopportun, des textes officiels. Mais, sous l'influence du Conseil de l'Europe, de la mondialisation et de l'accroissement des échanges qui en résulte, l'école va progressivement s'ouvrir à des partenariats extérieurs et intégrer d'autres aspects de la diversité, comme la construction européenne, les échanges internationaux ou les cultures régionales. La société française se reconnaît plurielle dans les années 1990, tandis que dans les années 2000, la formation des enseignants et les curricula traitent de la diversité culturelle, tout en initiant les élèves à sa compréhension, à la pluralité des références et, dans une moindre mesure, à une approche interculturelle. 
Le modèle français d'intégration à une culture commune républicaine par le biais de la forme scolaire demeure éminemment lié à la pression du politique et à la rhétorique égalitaire qui en émane, concernant le traitement des élèves, pourtant socialement et culturellement différents.

L'espace de liberté des enseignants pour une prise en considération de la diversité dans leur pédagogie semble plus réduit qu'ailleurs, d'autant plus que les questions identitaires peuvent favoriser des controverses et une prise de risque dans les pratiques quotidiennes, sans compter les éventuelles pressions de la hiérarchie très liée au politique.

Même si, depuis quelques années, la diversité est intégrée au programme de formation des enseignants (notamment au primaire), il n'existe toujours pas de formation en éducation interculturelle en tant que telle et, comme nous l'avons constaté, c'est souvent sur le tas, face à des situations pédagogiques infructueuses ou lors de l'arrivée de primo-arrivants ou d'enfants dits « du voyage ", que les enseignants essaient de mobiliser les arrière-plans culturels des élèves pour favoriser leur intégration et leurs apprentissages.

Le pédagogique demeure indissociable du politique, tandis que la pédagogie de l'action, qui vise à développer conscience critique, recherche, innovation, se limite à l'engagement de quelques enseignants.

\section{BIBLIOGRAPHIE}

ABDALLAH-PRETCEILLE M. (1999) : L'éducation interculturelle. Paris : PUF.

AUDUC J.L. (1996) : Enseigner en banlieue. Paris : Hachette.

BERQUE J. (1985) : L'immigration à l'école de la République. Rapport au ministère de l'Éducation. Paris : CNDP/la Documentation française.

BOULOT S., BOZON-FRADET D. (1988): Les immigrés et l'école, une course d'obstacles. Paris : L'Harmattan.

KERZIL J., VINSONNEAU G. (2004) : L'interculturel. Principes et réalités à l'école. Paris : SIDES.

LORCERIE F. (Ed.), (2003) : L'école et le défi ethnique. Paris : ESF.

MEUNIER O. (2008) : "Les approches interculturelles dans le système scolaire français : vers une ouverture de la forme scolaire à la pluralité culturelle? » Socio-logos, 3 [mis en ligne le 06 octobre 2008 : http://socio-logos.revues.org/1962].

VALLET L.A., CAILLE J.P. (1996) : Les élèves étrangers ou issus de l'immigration dans l'école et le collège français. Une étude d'ensemble. Les dossiers d'Éducation et formations, $\mathrm{n}^{\circ} 67$, ministère de l'Éducation nationale, DEP.

VAN ZANTEN A. (1997) : Le traitement des différences liées à l'origine immigrée à l'école française. In : N. Marouf, C. Carpentier (Ed.), Langue, école, identités, Paris : L'Harmattan, pp. 149-168. 